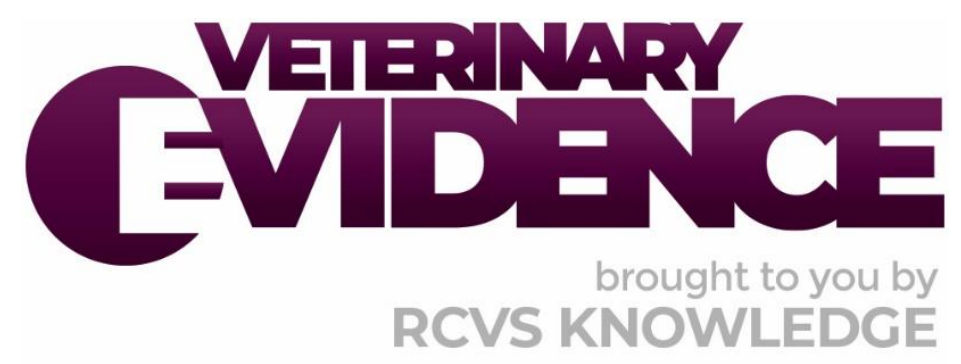

\title{
Tail docking and castrating lambs: does the administration of local anaesthetic or meloxicam reduce the pain response exhibited?
}

\author{
A Knowledge Summary by
}

Evangeline Dunthorne BVMSci (Hons)MRCVS ${ }^{{ }^{*}}$

\footnotetext{
${ }^{1}$ The University of Surrey School of Veterinary Medicine, Daphne Jackson Road, Guildford, GU2 7AL

* Corresponding Author (edunthorne13@gmail.com)
}

ISSN: 2396-9776

Published: 30 Jul 2021

in: The Veterinary Evidence journal Vol 6, Issue 3

DOI: https://doi.org/10.18849/ve.v6i3.462

Reviewed by: Diego Moya (DVM MSc PhD) and lain Richards

(BVSc MVetSci MRCVS)

Next Review Date: 06 Oct 2022 


\section{KNOWLEDGE SUMMARY}

\section{PICO question}

In healthy lambs, does the administration of local anaesthetic reduce the pain response after castration and tail docking compared to the administration of meloxicam?

\section{Clinical bottom line}

\section{Category of research question}

Treatment

\section{The number and type of study designs reviewed}

Three prospective randomised clinical trials (RCT) and one clinical trial without stated randomisation were critically reviewed

\section{Strength of evidence}

Moderate to strong evidence in terms of their experimental design due to having three RTCs which are all relatively recent research. However, their implementation is moderate to weak as they fail to prove the hypothesis

\section{Outcomes reported}

In all four studies there was improvement in the pain related behaviours post administration of anaesthesia or analgesia. There is conflicting evidence on meloxicam's efficacy, but this could be a result of time spent observing outcomes, which relates to the drugs onset of action and time of peak concentration. Lidocaine has consistently shown a reduction in acute abnormal behaviours irrespective of equipment used

\section{Conclusion}

Based on the studies appraised in this Knowledge Summary there is not enough evidence to determine whether local anaesthesia is more effective than meloxicam at reducing the pain exhibited by lambs undergoing castration or tail docking. It has been shown that the use of local anaesthesia in the form of injectable lidocaine will reduce acute pain displayed during marking but there remains conflicting evidence for meloxicam with likely benefits occurring after several hours

\section{How to apply this evidence in practice}

The application of evidence into practice should take into account multiple factors, not limited to: individual clinical expertise, patient's circumstances and owners' values, country, location or clinic where you work, the individual case in front of you, the availability of therapies and resources.

Knowledge Summaries are a resource to help reinforce or inform decision making. They do not override the responsibility or judgement of the practitioner to do what is best for the animal in their care. 


\section{Clinical Scenario}

You are a veterinarian who has been called for advice from a sheep farmer. The farmer is planning on performing all their castrates and tail docking themselves using rubber rings. They noticed last year many sheep exhibited behavioural and physical signs of pain after the procedures. They have asked whether they should use meloxicam or local anaesthesia to reduce this occurrence. Due to lack of licensing in the UK for either of these drugs for this purpose you are unsure which one to recommend (BVA, 2020).

\section{The evidence}

Four studies were found to be relevant to the PICO question, three of these were randomised and blinded (Kells et al., 2019; Smalls et al., 2014; and Smalls et al., 2020) reducing levels of selection and observer bias. The variables measured included; time spent performing different behaviours (Kells et al., 2019; Small et al., 2014; Kent et al., 1998) and time taken to 'mother-up', meaning time taken for lamb and mother to relocate each other after separation(Small et al., 2014; and Small et al., 2020). Within the behaviour category, acute pain related behaviour was observed alongside postures such as lying and standing. Included in the outcomes measured were parameters less relevant to the PICO such as cortisol levels (Kent et al., 1998) and wound development (Small et al., 2014) and therefore these were disregarded.

There was one study that contained both meloxicam and lidocaine and therefore fulfilled the inclusion criteria in its entirety; Kells et al. (2019). Additional to a control, groups were given either lidocaine subcutaneously (SC) or meloxicam intramuscularly (IM) or alternatively, given them both in combination. The group given both forms of analgesia was not important to this summary as it does not compare their efficacy. Meloxicam was given intramuscularly in the aforementioned study and buccally in the Small et al. (2014) study, whilst Kent et al. (1998) and Small et al. (2020) looked at the effect of lidocaine. All studies differed in route of administration of said anaesthesia and as such are difficult to directly compare.

It can be concluded from these studies that both types reduce pain responses post-marking but at different times, with meloxicam unsurprisingly providing more longer-term pain relief and lidocaine benefiting acutely. More evidence is required to directly compare the methods of anaesthesia/analgesia and decide which would be more efficacious in a clinical scenario.

\section{Summary of the evidence}

\section{Kells et al. (2019)}

\begin{tabular}{|c|c|}
\hline Population: & $\begin{array}{l}\text { New Zealand Merino, entire, singleton lambs, weighing } 15.4 \pm 0.23 \\
\mathrm{~kg} \text {, aged } 4-6 \text { weeks old }\end{array}$ \\
\hline Sample size: & 90 healthy male lambs \\
\hline Intervention details: & $\begin{array}{l}\text { The } 90 \text { lambs were allocated randomly into six treatment groups } \\
\text { (allocated via a number generator in Microsoft Excel): } \\
\text { - Group 1: C+D (castration and tail docking) without analgesia } \\
\text { - Group 2: sham group (handled but not castrated or docked) } \\
\text { - Group 3: C+D with local anaesthesia (LA) } \\
\text { - Group 4: C+D with meloxicam } \\
\text { - Group 5: C+D with LA and meloxicam administered } \\
\text { - Geparately } \\
\text { Experimental details: } \\
\text { - Day 1: the ewes and lambs were brought down from a hill } \\
\text { paddock (1.5 km) and held in a paddock adjacent to the } \\
\text { yards. } \\
\text { - Days } 2+3: \text { the group was moved to the yards. }\end{array}$ \\
\hline
\end{tabular}




\begin{tabular}{|c|c|}
\hline & $\begin{array}{l}\text { - On each of the } 3 \text { days: } 30 \text { lambs were weighed and } \\
\text { randomly assigned to one of the six treatment groups. Each } \\
\text { lamb was marked on its head and rump according to group } \\
\text { and then left in assigned pens for a minimum of } 30 \text { minutes. } \\
\text { - One pen was treated at a time with video data collected. } \\
\text { Lamb caught and held by researcher, analgesia given by } \\
\text { veterinary surgeon and procedure performed by farm staff. } \\
\text { - Lambs were in the pen for a total of } 6 \text { hours on their day of } \\
\text { testing, no feed or water given. } \\
\text { - After treatment lambs were ear tagged, vaccinated against } \\
\text { contagious pustular dermatitis and given vitamin B12 by the } \\
\text { farm staff and returned to their dams. } \\
\text { Procedure protocols: } \\
\text { - Castration: performed via rubber ring using an elastrator } \\
\text { - device. } \\
\text { - Tail docking: performed via a gas-heated docking iron. } 5 \text { ml (1 ml } 2 \% \text { lidocaine diluted to } 5 \text { ml in saline) } \\
\text { lignocaine SC into scrotal neck, spermatic cord and tail given } \\
\text { immediately prior to procedure. } \\
\text { - Meloxicam: } 1 \text { ml of } 2 \% \text { meloxicam IM immediately prior to } \\
\text { procedure. }\end{array}$ \\
\hline Study design: & Randomised blinded controlled trial \\
\hline Outcome studied: & $\begin{array}{l}\text { Behaviours were scored using behavioural observation research } \\
\text { interactive software (BORIS). } \\
\text { Pain response was measured using time spent performing eight } \\
\text { different behaviours (subjective): } \\
\text { - Normal standing/walking } \\
\text { - Abnormal standing/walking } \\
\text { - Twisted lying } \\
\text { - Frequency of foot kicks/stamps } \\
\text { - Turn to hindquarters } \\
\text { - Restlessness } \\
\text { - Hindlimb stretches } \\
\text { - Tail lifts } \\
\text { These behaviours were observed at three different points in time } \\
\text { relative to the procedure: } \\
\text { - Period A: } 30 \text { minutes pretreatment } \\
\text { - Period B: } 15-45 \text { minutes post-treatment } \\
\text { - Period C: } 4.15-4.75 \text { hours post-treatment }\end{array}$ \\
\hline $\begin{array}{l}\text { Main findings: } \\
\text { (relevant to PICO question): }\end{array}$ & $\begin{array}{l}\text { Groups } 1,3,4,5,6 \\
-\quad \text { In period B, the lambs showed a reduction in time spent } \\
\text { standing/walking normally compared to pretreatment. } \\
\text { Spent more time walking/standing abnormally than before } \\
\text { treatment. } \\
\text { Group } 4 \\
- \text { Exhibited behavior similar to those that did not receive } \\
\text { analgesia over the } 5 \text { hours after treatment. } \\
\text { Group } 3 \\
\text { - Reduced HL stretching, tail lifting and twisted lying in period } \\
\text { B. }\end{array}$ \\
\hline
\end{tabular}




\begin{tabular}{|c|c|}
\hline & $\begin{array}{l}\text { - Increased tail wags in period B. } \\
\text { - Little effect on time spent in abnormal standing/walking or } \\
\text { restlessness. } \\
\text { Groups } 5 \text { and } 6 \\
\text { - Twisted lying, hindlimb (HL) stretching, and tail lifting reduced } \\
\text { - Increased head/neck stretches. }\end{array}$ \\
\hline Limitations: & $\begin{array}{l}\text { - First } 15 \text { minutes in period B and C was discounted due to } \\
\text { disturbances from other pens, this would be when most acute } \\
\text { pain behaviours would be exhibited. } \\
\text { - Lambs in the SHAM group were distinguishable due to being } \\
\text { intact so bias was unavoidable. } \\
\text { - Behavior after } 4.75 \text { hours was not assessed. } \\
\text { - Meloxicam was given immediately before the procedure; it } \\
\text { requires longer for onset time (Woodland et al., 2019). } \\
\text { - Period of } 3 \text { hours between period B and C were not observed. } \\
\text { The lambs were given further treatment such as a vitamin B12 } \\
\text { injection which may cause drug interactions. }\end{array}$ \\
\hline
\end{tabular}

Small et al. (2014)

\begin{tabular}{|c|c|}
\hline Population: & $\begin{array}{l}\text { Merino lambs aged } 7-10 \text { weeks, weight } 19.7 \pm 0.38 \mathrm{~kg} \text {, single born } \\
\text { lambs. Maintained in field conditions. }\end{array}$ \\
\hline Sample size: & 60 healthy lambs \\
\hline Intervention details: & $\begin{array}{l}\text { Two groups (randomly allocated by a blinded operator selecting a } \\
\text { treatment chip from a box): } \\
\text { - } \quad 30 \text { lambs in placebo group: received } 1 \mathrm{ml} / 10 \mathrm{~kg} \text { of drug vehicle. } \\
\text { - } 30 \text { lambs in meloxicam group: received a target of } 1 \mathrm{mg} / \mathrm{kg} \\
\text { Experimental details: } \\
\text { - Two cohorts of } 30 \text { lambs were studied two weeks apart. } \\
\text { - } 6 \text { days before marking: Lambs caught and weighed. } \\
\text { - } 5 \text { days before marking: Ewes and lambs were run in the } \\
\text { observation paddock, during the day an observer walked } \\
\text { through the paddock to acclimatise the sheep to humans. } \\
\text { - Day of treatment: lambs separated from ewes and held in a } \\
\text { pen adjacent to the paddock. } \\
\text { - At } 2 \text { minutes intervals: lambs caught, weighed to the nearest } \\
\text { - } 100 \mathrm{~g} \text { and placed in a marking cradle. } \\
\text { Treatment was calculated and administered via a proprietary } \\
\text { dosing gun into the ventral aspect of the buccal sulcus between } \\
\text { - the molar teeth and the cheek. } \\
\text { - Tamb was then castrated via a marking knife. } \\
\text { - Tail docking carried out by a hot-iron docking knife. } \\
\text { Procedure protocol: } \\
\text { - Treatment was administered via oral mucosa immediately } \\
\text { - } \text { before the procedure } \\
\text { - Tastration via a knife }\end{array}$ \\
\hline Study design: & Double blinded randomised study \\
\hline
\end{tabular}




\begin{tabular}{|c|c|}
\hline Outcome studied: & $\begin{array}{l}\text { An ethogram was used, whereby the lambs behaviour was observed } \\
\text { every } 15 \text { minutes for } 8 \text { hours and again for } 45 \text { minutes at } 24 \text { hours } \\
\text { (behaviour is subjective): } \\
\text { - Standing (normal, hunched, stretched) } \\
\text { - Lying (ventral or lateral) } \\
\text { - Suckling } \\
\text { - Grazing } \\
\text { - Rulking (normal or stiff) } \\
\text { Time taken for lamb to mother-up (subjective): } \\
\text { - Time taken to suckle or; } \\
\text { - Time taken for ewe to show interest in the lamb. } \\
\text { - If }>5 \text { minutes categorised as a failure to mother-up. } \\
\text { Weight change and wound scores at } 4 \text { and } 7 \text { days after (objective): } \\
\text { - Wounds assessed on a 4-point scale: appearance and } \\
\text { swelling. }\end{array}$ \\
\hline $\begin{array}{l}\text { Main findings: } \\
\text { (relevant to PICO question): }\end{array}$ & 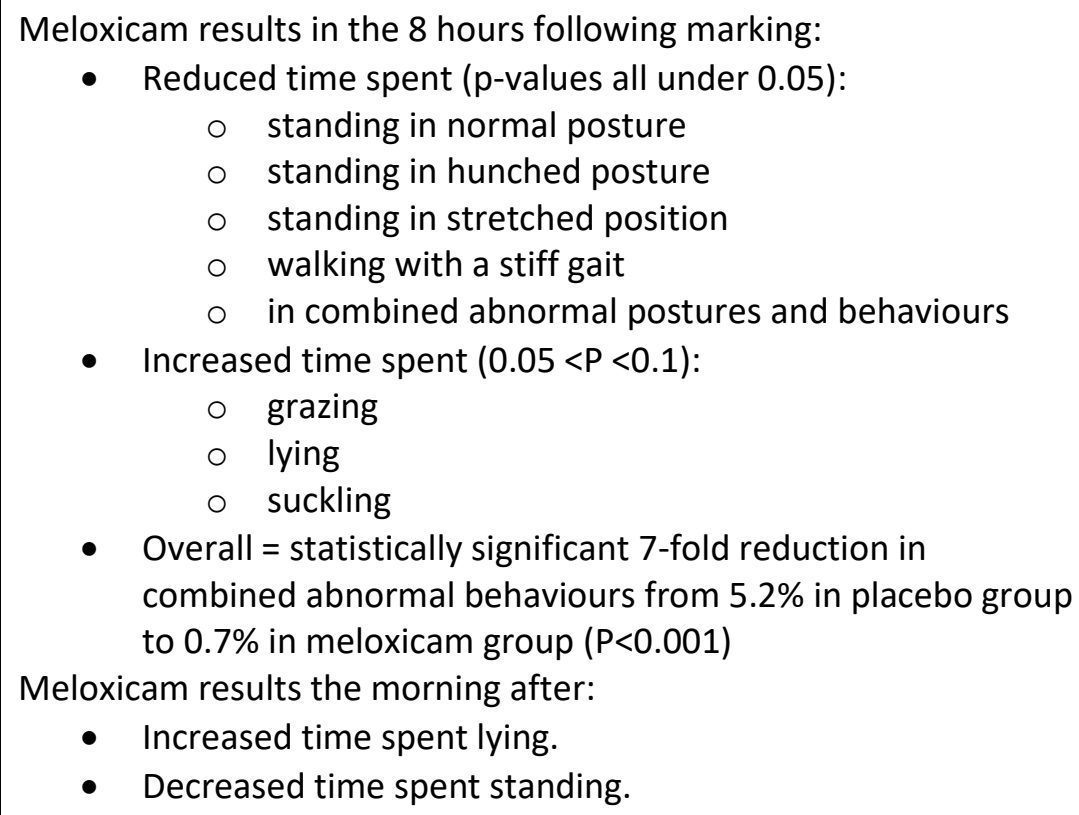 \\
\hline Limitations: & $\begin{array}{l}\text { - The pharmacokinetics of meloxicam efficacy is limited by } \\
\text { time for onset of action, Tmax is } 2.6 \text { hours for buccal } \\
\text { transmucosal formulation. } \\
\text { - The lambs in the first of the two cohorts were marked on } \\
\text { the flank which made them difficult to individually identify. } \\
\text { - There were two observers which could lead to varying } \\
\text { results and lack of standardisation. } \\
\text { - Parts of the ethogram used are vague e.g. 'standing with no } \\
\text { apparent abnormalities'. } \\
\text { - The dose of meloxicam: } \\
\text { O The lambs were categorised by weights in } 5 \mathrm{~kg} \\
\text { groupings and dose calculated in accordance with } \\
\text { the max weight in that group meaning some lambs } \\
\text { got more and some got less depending on where } \\
\text { they came in the group. }\end{array}$ \\
\hline
\end{tabular}




\begin{tabular}{|c|c|}
\hline Population: & Suffolk x Greyface lambs, average weight of 6-7 kg, 5-8 day old \\
\hline Sample size: & 120 healthy lambs \\
\hline Intervention details: & $\begin{array}{l}\text { Assigned eight to a group, each group divided into; with or without local } \\
\text { anaesthetic (groups balanced for sex, age and weight): } \\
\text { - Six castration groups } \\
\text { - Five tail docking groups } \\
\text { Experimental details: } \\
\text { - } 12 \text { hours before treatment the ewes and their lambs were } \\
\text { individually penned. } \\
\text { Procedure protocols: } \\
\text { - Castration: rubber ring applied to the neck of the scrotum } \\
\text { proximal to the testes. } \\
\text { - Docking: ring applied to the tail. } \\
\text { Bloodless castrator: rubber ring applied followed by application } \\
\text { of Burdizzo for } 10 \text { seconds across either the neck of the } \\
\text { scrotum proximal to the ring or across the width of the tail. } \\
\text { - LA: lignocaine hydrochloride } 2 \% \text { with adrenaline administered } \\
\text { in four different ways: } \\
\circ \quad 1 \text { - High pressure needleless injection } 0.2 \text { ml } \\
\text { intratesticular before ring application } \\
\circ \quad 2 \text { - High pressure needleless injection } 0.2 \text { ml into left } \\
\text { and right dorsolateral side of tail or right and left sides } \\
\text { of cranial neck of scrotum after ring application } \\
\text { o } 3 \text { - Same as } 2 \text { but following bloodless castrator } \\
\circ \quad 4-\text { Conventional injection } 0.2 \text { ml SC right and left } \\
\text { dorsolateral into tail or into spermatic cords }\end{array}$ \\
\hline Study design: & Non-randomised clinical control study \\
\hline Outcome studied: & $\begin{array}{l}\text { Behavioural responses (subjective): } \\
\text { - Lying and standing postures observed every } 2 \text { minutes for } 96 \\
\text { minutes and every } 6 \text { minutes for a further } 24 \text { minutes: } \\
\text { Lying and standing: } \\
\text { Normal lying, partial, full extension, lying } \\
\text { laterally with one shoulder on ground, } \\
\text { standing still, walking with swaying and } \\
\text { stamping movements. } \\
\text { - Active behaviours recorded continuously for } 96 \text { minutes: } \\
\quad \text { Getting up and down, rolling, jumping, stamping, } \\
\text { kicking, easing quarters, head turning and vocalisation. } \\
\text { Cortisol assays (objective): } \\
\text { - } 20 \text { and } 0 \text { minutes pretreatment. } \\
20,40,60,80,120,180 \text { minutes post-treatment. }\end{array}$ \\
\hline $\begin{array}{l}\text { Main findings: } \\
\text { (relevant to PICO question): }\end{array}$ & $\begin{array}{l}\text { The sum of incidences of restlessness, rolling, stamping, kicking and } \\
\text { easing quarters (REQ): } \\
\text { - LA at the time of castration or docking reduced the mean REQ } \\
\text { of all constituents and time spent in abnormal postures: } \\
\circ \quad \text { Tail docking: } 84 \% \text { reduction in active behaviour and } \\
69 \% \text { reduction in abnormal postures. } \\
\circ \quad \text { Castration: } 68 \% \text { reduction in active behaviour, } 58 \% \\
\text { reduction in abnormal postures. }\end{array}$ \\
\hline
\end{tabular}




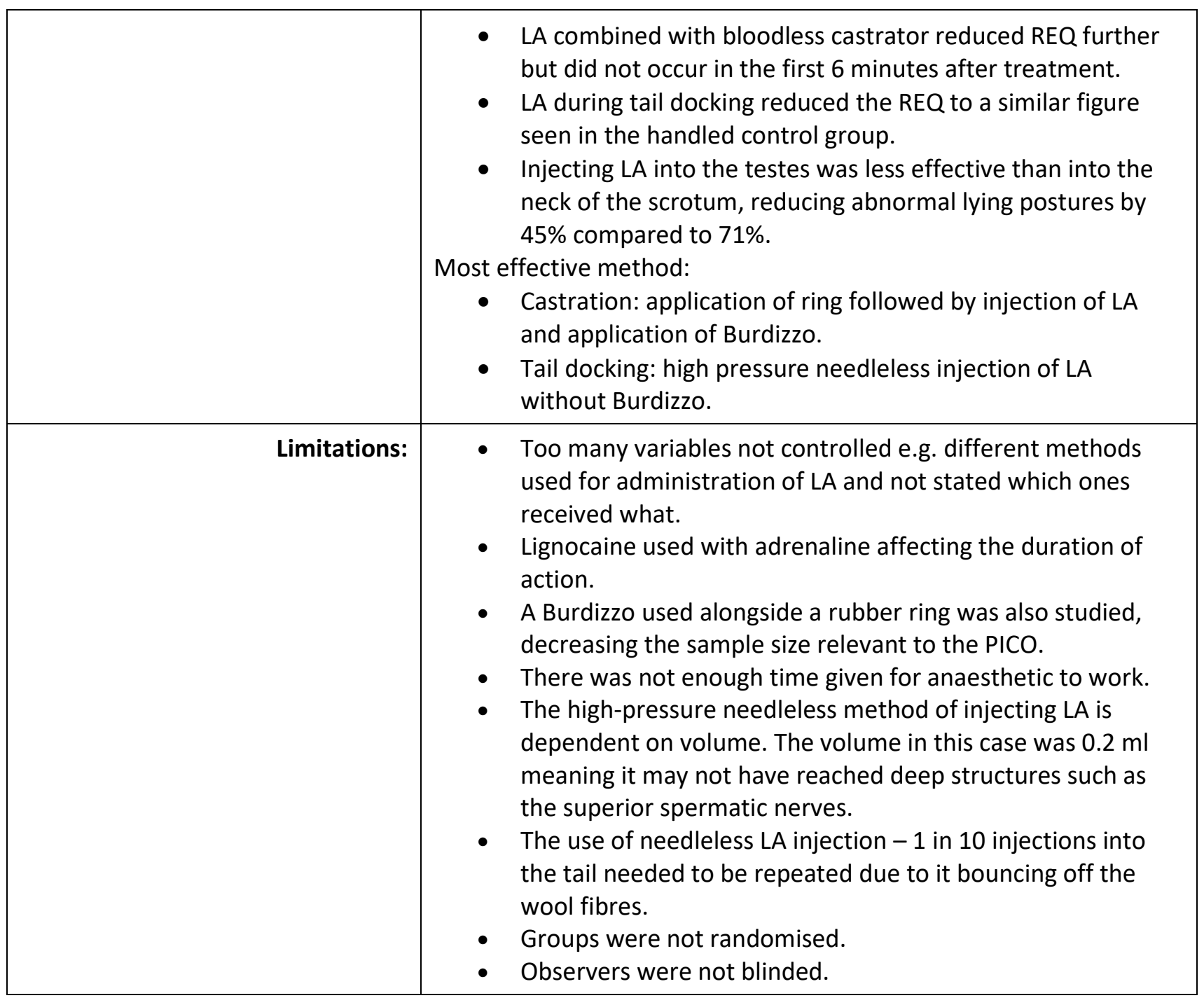

Small et al. (2020)

\begin{tabular}{|c|c|}
\hline Population: & $\begin{array}{l}\text { Lambs aged } 4-10 \text { weeks, body weight } 9.4-31.9 \mathrm{~kg} \text {, Dorset } x \text { Merino } x \\
\text { Border Leicester, mixture of single and twin lambs }\end{array}$ \\
\hline Sample size: & 150 healthy lambs \\
\hline Intervention details: & $\begin{array}{l}\text { Randomly allocated to three groups: } \\
\text { - Handled in a lambing cradle (sham) } \\
\text { - Handled and marked with rubber rings (ring) } \\
\text { - Handled and marked with rubber rings and treated with } 30 \\
\text { Experimental details: } \\
\text { - Day 0: ewes and lambs separated. Lambs were each } \\
\text { weighed, sex identified, and ear tagged. } \\
\text { - The lambs were then randomly allocated to treatment } \\
\text { groups and separated into female and male groups. } \\
\text { Groupings were made up of } 30 \text { female and } 30 \text { males in NNLA } \\
\text { and Ring groups and a mix of } 30 \text { male and female lambs in } \\
\text { the sham group. } \\
\text { - Treatment applied and recorded, lambs marked and then } \\
\text { released into an observation paddock. }\end{array}$ \\
\hline
\end{tabular}




\begin{tabular}{|c|c|}
\hline & $\begin{array}{l}\text { - Three observers recording behaviours using an ethogram. } \\
\text { Procedure protocols: } \\
\text { - Tail docking: via a rubber ring at the level of the third coccygeal } \\
\text { joint of the tail. } \\
\text { - Castration: rubber ring placed at the neck of the scrotum. } \\
\text { - } \quad \text { Numnutrator pliers for group } 2 \text {. } \\
\circ \quad \text { Injects lignocaine hydrochloride } 1.5 \mathrm{ml} \text { of } 20 \mathrm{mg} / \mathrm{ml} \\
\text { (SC) at the time of rubber ring placement. } \\
\circ \text { Midline into dorsal aspect of tail or midline into } \\
\text { posterior aspect of scrotal neck. }\end{array}$ \\
\hline Study design: & Blinded randomised controlled trial \\
\hline Outcome studied: & $\begin{array}{l}\text { Time to mother-up: } \\
\text { - Assessed for } 180 \text { seconds after release of lambs into the } \\
\text { observation paddock. } \\
\text { - If }>180 \text { seconds it was considered a failed to mother-up. } \\
\text { Acute pain related behaviours at 5, 20, 35, } 50 \text { minutes (subjective): } \\
\text { - Restlessness, kicking/stamping, rolling, jumping, pawing, } \\
\text { licking/biting wound site, suckling, easing quarters. } \\
\text { Postures at } 10 \text { minutes intervals } 60-180 \text { minutes (subjective): } \\
\text { - Normal standing and abnormal standing. } \\
\text { - Standing other, normal walking, abnormal walking, walking } \\
\text { other, running, jumping, grazing, suckling, playing, normal lying, } \\
\text { abnormal lying, lying intention, lateral lying, ventral lying other, } \\
\text { rolling. }\end{array}$ \\
\hline $\begin{array}{l}\text { Main findings: } \\
\text { (relevant to PICO question): }\end{array}$ & $\begin{array}{l}\text { Mothering-up: } \\
\text { - Female lambs had } 0.46 \text { times less chance of mothering up with } \\
\text { ring treatment compared to NNLA treatment }(P=0.015) \text {. } \\
\text { - Not significant in male lambs. } \\
\text { Pain behaviour: } \\
\text { - NNLA was less than ring at } 5 \text { minutes }(P<0.001) \text { and } 20 \text { minutes } \\
\text { ( } P=0.001) \text {. } \\
\text { Ring and NNLA did not differ at } 35 \text { or } 50 \text { minutes in males, but } \\
\text { did differ at } 35 \text { minutes in females }(P=0.007) \text {. } \\
\text { Postural behaviours: } \\
\text { - NNLA and ring did not differ at any time point between } 60 \text { and } \\
180 \text { minutes. } \\
\text { Total lying times: } \\
\text { - Males: } \\
\quad \text { NNLA spent more time lying at } 80 \text { minutes. } \\
\circ \quad \text { NNLA spent more time lying at } 90 \text { and } 130 \text { minutes. } \\
\text { - Females: } \\
\circ \quad \text { NNLA differed from ring at } 60 \text { minutes. }\end{array}$ \\
\hline Limitations: & $\begin{array}{l}\text { - Three observers reducing standardisation. } \\
\text { - The efficacy is limited to the duration of action of lignocaine } 2 \% \text {. } \\
\text { - Looked at } 2 \text { commercial farms reducing the level of control and } \\
\text { adding variability. } \\
\text { - This study Is focused on the efficacy of the Numnuts }{ }^{\circledR} \text { device } \\
\text { more so than the efficacy of LA itself. } \\
\text { - Reduced volume of } 2 \% \text { lignocaine, should be about } 4 \mathrm{mg} / \mathrm{kg} \\
\text { into the scrotal neck and spermatic cords (Mellema et al., } \\
\text { 2006). }\end{array}$ \\
\hline
\end{tabular}


- The behaviours were measured in 1 minute blocks at given time points rather than continuously.

\section{Appraisal, application and reflection}

According to The Mutilations Regulations 2007 (The Mutilations Act, 2007), if a lamb is aged 3 months or older at the time of tail docking or castration an anaesthetic must be used. Tail docking is routinely carried out to prevent faecal or urine contamination around the tail which can lead to flystrike and in worse case scenarios death. Castrations are carried out to reduce aggressive behaviours making animal handling easier and prevent unwanted pregnancies of ewes (BVA., 2020). This paper looks at the current anaesthesia and analgesia used in lambs during these procedures and compares their efficacy in the hope of encouraging its widespread implementation.

The strongest evidence for this PICO lies in Kells et al. (2019); it contains both meloxicam and lidocaine administration and compares their benefits. This study demonstrates a conventional method of lidocaine infusion subcutaneously (SC) into the scrotal neck, spermatic cord and tail, but the method of meloxicam administration intramuscularly (IM) precastration/docking is not highly reported. In a study based on meloxicam efficacy in sheep, it is advised that a dose of $1 \mathrm{mg} / \mathrm{kg}$ be given IM (Woodland et al., 2019), whereas, in Kells et al. (2019) the dose worked out at $20 \mathrm{mg} / \mathrm{ml}$ making it is more than double the required amount. Alongside this; length of time needed for both medications to take effect was not allowed as they were given just before the procedure. It has been demonstrated that 10-15 minutes should be permitted after LA administration for it to take effect (Wood et al., 1991). In addition, IM meloxicam reaches peak plasma concentration (Tmax) at 2-3 hours post administration (Woodland et al., 2019), therefore longer observation of pain behaviours would have been beneficial. In this study pain related behaviour including reduced time spent lying normally and increased time spent standing/walking abnormally was still seen after 5 hours observation. Kells et al. (2019) states no difference between the meloxicam group and the group that did not receive analgesia, but this may be due to the route of administration, time outcome was measured or onset of action. Moreover, no $p$-value was given for these results and so their significance is unknown. There is limited literature about onset of action time for meloxicam in sheep in the UK due to it being given on the cascade. Meloxicam was given buccally in Small et al. (2014) with its Tmax time stated as 2.6 hours for oral administration, despite this it was given immediately before the procedure similarly to Kells et al. (2019).

The route of administration also differed between studies for lidocaine. In the studies Kells et al. (2019) and Kent et al. (1998) it was given SC into the scrotal neck, spermatic cord and tail, in the latter, it was sometimes given via a high-pressure needleless injection. In Small et al. (2020) it was given by a piece of equipment called Numnuts ${ }^{\circledR}$ that injects at the time of castration, it can be argued that the aim of this study was more about the efficacy of the Numnuts ${ }^{\circledR}$ device rather than the benefits of lidocaine at marking. Numnuts ${ }^{\circledR}$ is for application in 4-8 week old lambs weighing 10-20 kgs and the active ingredient NumOcaine ${ }^{\circledR}$ is approved in Australia and New Zealand but not the UK. Additionally, lambs tend to be castrated before 4-8 weeks old in the UK and so their use in the UK is limited (Numnuts., n.d.). In Kent et al. (1998) it was not stated who received which method of lidocaine administration, for example who received high-pressure needleless injection or conventional SC injection and where this injection was given; either intratesticular or in the spermatic cord/neck of the scrotum. This makes the evidence weaker due to little control over the variables. The study later states that there was no significant difference between responses to route of administration, but this is hard to support with such a reduced sample size after subdividing them. Additionally, lidocaine was used with adrenalin increasing its duration of action and reducing its use in this PICO. Overall, the paper provides insufficient evidence as there were too many protocols being tested with little confirmation on groupings, method used or clearly stated aims.

Timing of measuring outcomes in all instances played a large part in what information was gathered. It could be said that for Kent et al. (2019) longer than 4 hours may have given more information on meloxicam and the delay of measurement at 15 minutes could have restricted what outcomes from lidocaine were seen. 
Lidocaine has a variable duration of action in sheep of about 90 minutes and a short onset of action of 2-5 minutes (Depenbrock, 2017) so any data collected between 0-30 minutes is imperative. Similarly, in Small et al. (2020) the behaviours were observed in 1 minute blocks rather than continuously allowing large windows for missing key signs. However, the best timetable for measurements was in both Small et al. (2014) and Small et al. (2020) which studied pain behaviours at 5, 20, 35, 50 minutes for lidocaine and for 8 hours and then again at 24 hours for meloxicam.

It may be difficult to compare the results between the studies due to the range of marking protocols used. Kells et al. (2019) used a rubber ring for castration and hot iron for docking, Small et al. (2014) used a knife for castration and hot iron for docking, Kent et al. (1998) and Small et al. (2020) used rubber rings for both procedures which was sometimes followed by a bloodless castrator (Kent et al., 1998). It has been shown that the method affects levels of stress and therefore can have an impact on behavioural responses (Molony et al., 1993), influencing the results in the trials. All except Kent et al. (1998) were randomised and blinded, reducing bias at selection and observation. Despite stating that the observer was blinded to treatment groups, in Kell et al. (2019) lambs in the SHAM group were distinguishable from the treated group, but this has little bearing on our review as a comparison is only needed between lambs that were castrated/docked with or without analgesia.

Most of the studies have an adequate sample size with the smallest being 60 lambs (Small et al., 2014). A smaller sample reduces the power of the study directly impacting the studies ability to demonstrate a statistical difference. Statistical significance depends on sample size and effect size, so even if the effect size is large if the sample size is small the results are not significant (Sullivan \& Feinn, 2012), hence the data in Kent et al. (1998) being of reduced value once the groups had been designated. Three of the studies are based outside of the UK making their transferability more difficult. Kent et al. (1998) was based in Scotland but this paper is of least use. A difference created by location is the breeds examined, which may affect the stoic nature of the lambs. In the UK most lambs are ringed before 7 days old to conform to UK legislation, in Australia and New Zealand lambs are typically marked between 4-6weeks old. This is demonstrated in these studies whereby the populations of lambs outside the UK exceed 7 days. Many lambs in Australia and New Zealand are born outdoors and require gathering up for marking which is why it is difficult to perform the task in under 7 days (Numnuts, n.d.). This means that these studies have a greater resonance with UK farmers with hill sheep flocks.

Discouraging the non-randomised trial due to its weaknesses outlined above, the other three all show an improvement in aberrant behaviour. Lidocaine showed an acute effect after the procedure for example a significant reduction in pain behaviours at $5(P<0.001)$ and 20 minutes $(P=0.001)$ were observed (Small et al., 2020). Meloxicam showed longer-term effects (Small et al., 2014), at 8 hours after marking there was a statistically significant reduction in combined abnormal behaviours $(P<0.001)$ from $5.2 \%$ in the placebo group to $0.7 \%$ in the meloxicam group. Kent et al. (2019) demonstrated that in combination they proved more advantageous, showing a reduction in twisted lying, hindlimb stretching and tail lifting but the $p$-value was not stated and as such its significance cannot be determined. In Small et al. (2014) it was stated that $0.1>P>0.05$ still indicates a tendency towards significance but typically $\mathrm{P}>0.05$ supports evidence for the null hypothesis and so results including meloxicam increasing time spent grazing, lying and suckling can be disputed.

In conclusion, more evidence is required to compare the benefits of meloxicam to lidocaine when given before castration or tail docking. In the meantime, for lambs over the age of 3 months old anaesthesia must be used. Despite meloxicam having conflicting evidence, the use of LA or non-steroidal anti-inflammatories (NSAIDs) have their part to play in reducing pain post-procedure. Buccal meloxicam will cause delayed analgesia and SC lidocaine provides acute pain relief; they remain strong methods of pain control and current research is taking place for Numnuts ${ }^{\circledR}$ to be introduced in the UK. Using both an NSAID and local anaesthesia in combination requires more research to prove its efficacy and safety and is not covered by this PICO. As a result of the studies being taken from Australian and New Zealand flocks, the studies appraised in this paper will have more relevance to UK hill flocks and those castrating/docking late. Additionally, lidocaine does not have a maximum 
residue level (MRL), and both lidocaine and meloxicam are not licensed in the UK for this purpose. Subsequently, these papers are limited for practical application in the UK.

\section{Methodology Section}

\begin{tabular}{|c|c|}
\hline \multicolumn{2}{|l|}{ Search Strategy } \\
\hline $\begin{array}{r}\text { Databases searched and dates } \\
\text { covered: }\end{array}$ & $\begin{array}{l}\text { CAB Abstracts on OVID interface (1973- Oct 2020) } \\
\text { PubMed on the NCBI website (1958- Oct 2020) }\end{array}$ \\
\hline Search terms: & $\begin{array}{l}\text { CAB Abstracts and PubMed: } \\
\text { 1. (lamb* or sheep) } \\
\text { 2. (castrat* or tail docking or marking) } \\
\text { 3. (meloxicam or local anaesthesia or analgesia or lidocaine or } \\
\text { lignocaine) } \\
1 \text { AND } 2 \text { AND } 3\end{array}$ \\
\hline Dates searches performed: & 6 Oct 2020 \\
\hline \multicolumn{2}{|l|}{ Exclusion / Inclusion Criteria } \\
\hline Exclusion: & $\begin{array}{l}\text { Paper not available in English } \\
\text { Paper cannot be accessed } \\
\text { Paper was a review or conference paper } \\
\text { The study: } \\
\text { - Was not relevant to the PICO } \\
\text { - Did not contain meloxicam or local anaesthesia } \\
\text { - Use of a different NSAID } \\
\text { - Use of different local anaesthetic to lidocaine } \\
\text { - Did not look at pain response } \\
\text { - Lidocaine given topically rather than injected } \\
\text { - Looking at mulesing lambs instead of castration or tail } \\
\text { - docking } \\
\text { - Ine study was on sheep not lambs }\end{array}$ \\
\hline Inclusion: & $\begin{array}{l}\text { Any relevant primary research paper which compared the pain } \\
\text { response with meloxicam or topical anaesthesia }\end{array}$ \\
\hline
\end{tabular}

\begin{tabular}{|l|c|c|c|c|c|c|}
\hline \multicolumn{2}{|l|}{ Search Outcome } \\
\hline \multicolumn{1}{|c|}{ Database } & $\begin{array}{c}\text { Number } \\
\text { of } \\
\text { results } \\
\text { relevant to } \\
\text { the PICO }\end{array}$ & $\begin{array}{r}\text { Excluded - } \\
\text { Not } \\
\text { Inaccessible }\end{array}$ & $\begin{array}{c}\text { Excluded - } \\
\text { Conference } \\
\text { paper }\end{array}$ & $\begin{array}{c}\text { Excluded - } \\
\text { Review }\end{array}$ & $\begin{array}{c}\text { Total } \\
\text { relevant } \\
\text { papers }\end{array}$ \\
\hline $\begin{array}{l}\text { CAB } \\
\text { Abstracts }\end{array}$ & 23 & 13 & 2 & 3 & 2 & 3 \\
\hline PubMed & 44 & 33 & 3 & 0 & 4 & 4 \\
\hline Total relevant papers when duplicates removed & & & 4 \\
\hline
\end{tabular}




\section{CONFLICT OF INTEREST}

The author declares no conflict of interest.

\section{REFERENCES}

1. British Veterinary Association. (2020). Sheep castration, tail docking, and pain management. 1-7. Available at: https://www.bva.co.uk/media/3364/sheep-castration-tail-docking-and-painmanagement-final.pdf [Accessed 1 November 2020]

2. Depenbrock, S. (2017). Ruminant Field Anaesthesia and Analgesia. Penn Conference. 1-5.

3. Kells, N.J., Beausoleil, N.J., Godfrey, A.J.R., Littlewood, K.E., Ward, R.N. \& Johnson, C.B. (2019). Effect of analgesic strategies on pain behaviour associated with combined ring castration and hot iron tail docking in Merino lambs. Applied Animal Behaviour Science. 222.

DOI: http://dx.doi.org/10.1016/i.applanim.2019.104914

4. Kent, J.E., Molony, V. \& Graham, M.J. (1998). Comparison of methods for the reduction of acute pain produced by rubber ring castration or tail docking of week-old lambs. The Veterinary Journal. 155(1), 39-51. DOI: https://doi.org/10.1016/S1090-0233(98)80033-6

5. Molony, V., Kent, J.E. \& Robertson, I.S. (1993). Behavioural responses of lambs of three ages in the first three hours after three methods castration and tail docking. Research in Veterinary Science. 55(2), 236-245. DOI: http://dx.doi.org/10.1016/0034-5288(93)90087-V

6. (n. d.). Numnuts ${ }^{\oplus}$ availability in the UK. Available at: https://numnuts.store/is-numnuts-available-inthe-uk/ [Accessed 27 December 2020]

7. Small, A., Belson, S., Holm, M. \& Colditz, I.G. (2014). Efficacy of a buccal meloxicam formulation for pain relief in Merino lambs undergoing knife castration and tail docking in a randomized field trial. Australian Veterinary Journal. 92(10), 318-388. DOI: http://dx.doi.org/10.1111/avj.12241

8. Small, A.H., Jongman, E.C., Niemeyer, D., Lee, C. \& Colditz, I.G. (2020). Efficacy of precisely injected single local bolus of lignocaine for alleviation of behavioural responses to pain during tail docking and castration of lambs with rubber rings. Research in Veterinary Science. 133, 210-218. DOI: http://dx.doi.org/10.1016/j.rvsc.2020.09.025

9. Sullivan, G.M. \& Feinn, R. (2012). Using Effect Size - or Why the $P$ Value Is Not Enough. Journal of Graduate Medical Education. 4(3), 279-282. DOI: https://dx.doi.org/10.4300\%2FJGME-D-12-00156.1

10. (2007). The Mutilations (Permitted Procedures) (England) Regulations 2007. Available at: https://www.legislation.gov.uk/ukdsi/2007/9780110757797/contents/data.html [Accessed 1 November 2020]

11. Wood, G.N., MoLony, V., Fleetwood-Walker, S.M., Hodgson, J.C. \& Mellor, D.J. (1991). Effects of local anaesthesia and intravenous naloxone on the changes in behaviour and plasma concentrations of cortisol produced by castration and tail docking with tight rubber rings in young lambs. Research in Veterinary Science. 51(2), 193-199. DOI: http://dx.doi.org/10.1016/0034-5288(91)90013-E

12. Woodland, A.N., Van der Saag, D., Kimble, B., White, P.J., Govendir, M. \& Lomax, S. (2019). Plasma pharmacokinetic profile and efficacy of meloxicam administered subcutaneously and intramuscularly to sheep. PLOS ONE. DOI: http://dx.doi.org/10.1371/journal.pone.0215842 


\section{EVIIDEFeE

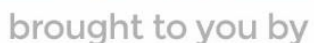 \\ RCVS KNOWLEDGE}

\section{Intellectual Property Rights}

Authors of Knowledge Summaries submitted to RCVS Knowledge for publication will retain copyright in their work, and will be required to grant RCVS Knowledge a non-exclusive license of the rights of copyright in the materials including but not limited to the right to publish, re-

publish, transmit, sell, distribute and otherwise use the materials in all languages and all media throughout the world, and to license or permit others to do so.

\section{Disclaimer}

Knowledge Summaries are a peer-reviewed article type which aims to answer a clinical question based on the best available current evidence. It does not override the responsibility

of the practitioner. Informed decisions should be made by considering such factors as individual clinical expertise and judgement along with patient's circumstances and owners' values. Knowledge Summaries are a resource to help inform and any opinions expressed within the Knowledge Summaries are the author's own and do not necessarily reflect the view of the RCVS Knowledge. Authors are responsible for the accuracy of the content. While the

Editor and Publisher believe that all content herein are in accord with current recommendations and practice at the time of publication, they accept no legal responsibility

for any errors or omissions, and make no warranty, express or implied, with respect to material contained within.

For further information please refer to our Terms of Use.

RCVS Knowledge is the independent charity associated with the Royal College of Veterinary Surgeons (RCVS). Our ambition is to become a global intermediary for evidence based veterinary knowledge by providing access to information

that is of immediate value to practicing veterinary professionals and directly contributes to evidence based clinical decision-making.

\section{https://www.veterinaryevidence.org/}

RCVS Knowledge is a registered Charity No. 230886.

Registered as a Company limited by guarantee in England and Wales No. 598443.

Registered Office: Belgravia House, 62-64 Horseferry Road, London SW1P 2AF

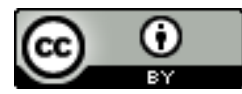

This work is licensed under a Creative Commons Attribution 4.0 International License. 